\title{
Cutaneous silent period in masseter muscles: a clinical and electrodiagnostic evaluation
}

\author{
B. W. ONGERBOER DE VISSER AND C. GOOR ${ }^{1}$ \\ From the Departments of Clinical Neurophysiology of the Municipal Hospital Leyenburg, \\ The Hague, and the University Hospital, Leiden, The Netherlands
}

SYNOPSIS In 35 normal subjects electromyographic silent periods were constantly evoked bilaterally in the masseter muscles during maximal contraction after unilateral electrical stimulation over the infraorbital or mental nerve. Findings in this study and data obtained in 30 patients suffering from trigeminal (26) and facial (four) nerve lesions suggest that the silent period evoked according to our methods is cutaneous in origin. The trigeminal sensory root forms the afferent limb of the silent period reflex. Its central pathway is thought to pass both crossed and uncrossed through the pons. Determination of the cutaneous silent period might be of value for the demonstration of trigeminal nerve lesions and to supplement results concerning other brain-stem reflexes.

The electromyographic silent period (SP) refers to a transitory, relative or absolute decrease of EMG activity evoked in the midst of an otherwise sustained contraction (Shahani and Young, 1973). The term SP should be reserved for reflex pauses following a stimulus of some kind -for example, an electrical shock - to peripheral nerves and the skin overlying them; phasic reflex contractions - for instance, a tendon tap; or sudden decreases in the load against which a muscle is contracting (unloading reflex). Several factors are involved in the SP, including recurrent inhibition of motoneurones (Renshaw inhibition), Golgi tendon organ inhibitory activity, a pause in muscle spindle input, cutaneous factors, and descending impulses from subcortical or cortical areas, as well as other mechanisms yet to be described (Shahani and Young, 1973; Struppler, 1975).

In the masseter muscles SPs have been observed after acoustic stimuli, a tap on the chin, and stimulation applied to the surface of the tongue and to the masseter muscle belly (Hoffman and Tönnies, 1948; Struppler et al., 1960;

\footnotetext{
1 Address for correspondence: Dr C. Goor, Department of Clinical Neurophysiology, Leyenburg Hospital, The Hague, Netherlands. (Accepted 31 December 1975.)
}

Hufschmidt and Spuler, 1962; Shahani and Young, 1973; Meier-Ewert et al., 1974). Some of the authors support the hypothesis that Golgi tendon organ activity plays a significant role in the genesis of masseter SPs, but others assign this role to spindle pause.

Because of the different anatomical tracts involved, the trigeminal nerve may be of special interest for the investigation of the various factors influencing the inhibition of motoneurones. The proprioceptive fibres from masseter spindles whose cells lie in the mesencephalic trigeminal nucleus and the efferent fibres from trigeminal motoneurones both pass through the so-called trigeminal motor root (Szentágothaï, 1948; McIntyre, 1951; McIntyre and Robinson, 1959; Ongerboer de Visser and Goor, 1976). Exteroceptive fibres run in the trigeminal sensory root, their cells lying in the Gasserian ganglion. Collateral branches terminate in the main sensory nucleus in the pons or in the trigeminal spinal tract and nucleus in the medulla oblongata. It is supposed that proprioceptive fibres from tendon organs also travel in the sensory root (Szentágothaï, 1948; Hufschmidt and Spuler, 1962).

The purpose of the present study was to investigate cutaneous factors influencing the 
masseter SP. A group of normal subjects and a group of patients suffering from trigeminal nerve lesions were studied. To determine whether a facial muscle input plays a role, a group of patients with a peripheral facial palsy was also investigated.

\section{METHODS}

EMG activity was recorded simultaneously from both masseter muscles with concentric needle electrodes. The subject was instructed to maintain maximal clenching of the jaws, which was monitored by both the subject and the observer by the loudspeaker of the electromyograph, and by the observer via the interference pattern on the oscilloscope.

In 30 normal subjects (age range 23-74 years, mean 41.7 years) SPs were evoked by percutaneous unilateral square wave electrical stimuli lasting $0.2 \mathrm{~ms}$ at $100-200 \mathrm{~V}$, applied successively to the mental, infraorbital, and supraorbital nerves in 15 of the subjects and only to the mental nerve in the others. The stimulator triggered the sweep of a dual-trace persistence oscilloscope.

In five normal adults we attempted to stimulate only cutaneous afferent fibres electrically. Trains of stimuli, $5-10 \mathrm{~ms}$ of $0.1-0.3 \mathrm{~ms}$ pulses repeated at a frequency of 300 per second, were delivered through bipolar stimulating electrodes placed intracutaneously on the right or left side of the chin. The voltage $(10-15 \mathrm{~V})$ was adjusted so that it lay above the threshold for subjective sensation-that is, moderately strong but painless tingling.

For all individuals, three responses were usually superimposed on the storage oscilloscope for subsequent photography and measurement. Figure $1 \mathrm{~A}$ shows the methods used for measurement. The duration of the SP was taken as the interval between the onset $(\mathrm{O})$ of the silence and the beginning of the uninterrupted voluntary activity (X). The latency time was measured from the stimulus (S) to the onset of the silence (Higgins and Lieberman, 1968; McLellan, 1973). In the patients, furthermore, the blink and jaw reflexes, recorded by the methods reported elsewhere (Ongerboer de Visser and Goor, 1974), and masseter EMGs were investigated.

Thirty selected patients (age range 14-76, mean 51.7 years) were studied. In 17 surgically treated cases the lesions were located outside the brain stem: 12 cerebellopontine angle tumours, one hemimandibularectomy with excision of the masseter muscle as treatment for a tumour, two retrogasserian root section (Dandy), one gasserian coagulation (Kirschner), and one infraorbital and inferior dental nerve exeresis. The last four of these operations were performed as treatment for trigeminal

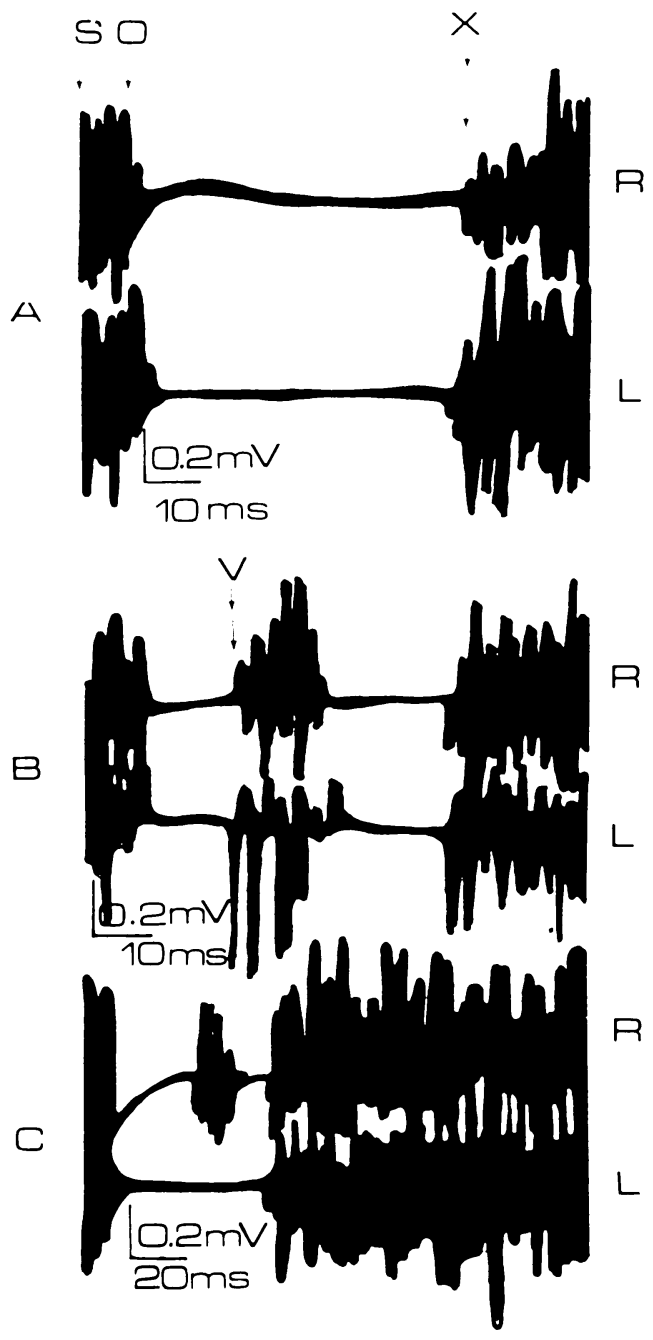

FIG. 1 Silent periods $(O-X)$ in masseter muscles during maximal contraction in normal subjects. $A$ and $B$ : silent periods after percutaneous mental nerve stimulation $(S)$. C: silent periods after intracutaneous stimulation applied to the right side of the chin. $B$ and $C$ showed a break-through voluntary activity $(V)$.

neuralgia. In nine of the patients the trigeminal nerve lesions were situated inside the brain stem. Three of these patients with unilateral midbrain lesions (one vascular and two tumorous verified at surgery) showed a crossed hemiparesis with third cranial nerve involvement. Two cases concerned pontine tumours. One of these patients with a tumour located deep in the pons showed slurred 


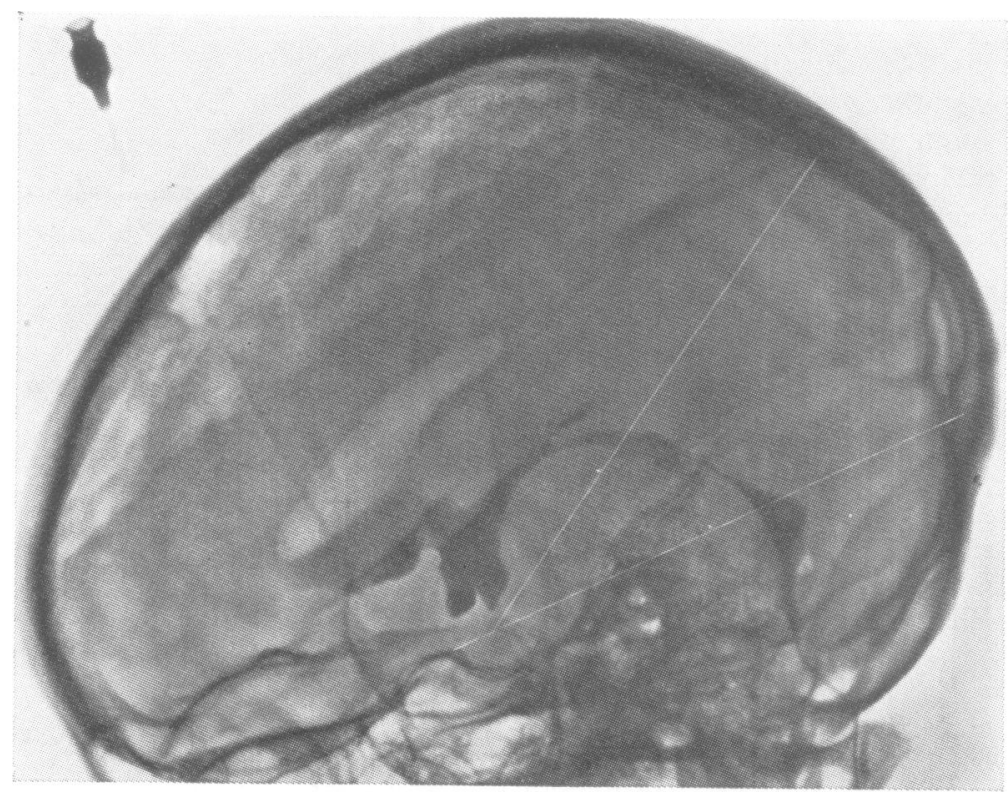

FIG. 2 Ventriculography (meglumine iocarmate) in the patient with a tumour located deep in the pons. The fourth ventricle is elevated.

speech, a horizontal conjugate gaze paresis, and an otherwise unspecific clinical picture; this tumour was verified both angiographically and ventriculographically (Fig. 2). The other patient with a right pontine localization of the tumour verified at necropsy (Fig. 3) showed a crossed hemiparesis with sixth, seventh, and eighth cranial nerve involvement and non-function of both the trigeminal sensory and motor roots.

Four of these nine cases had clinical features characteristic of the Wallenberg syndrome, where infarction typically involves the spinal tract and nucleus of the trigeminal nerve in addition to other structures (Wilkins and Brody, 1970).

In four patients with peripheral facial paralysis and normal trigeminal nerve functions, SPs were also provoked in the masseter muscles.

\section{RESULTS}

After unilateral percutaneous supramaximal stimulation applied to the infraorbital or mental nerve, all of the 30 normal subjects showed a SP in the masseter muscles on both sides (Fig. 1A and B). After supraorbital nerve stimulation, on the contrary, absolute electrical silences were briefly observed in only four of the 15 subjects.

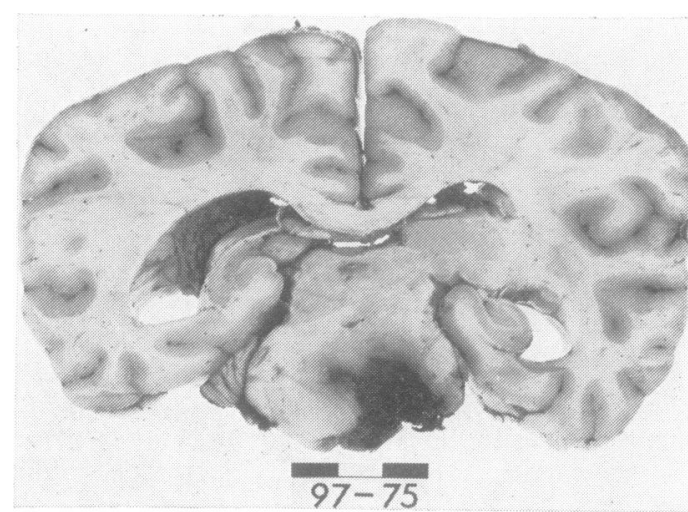

FIG. 3 Haemorrhage in the tumour situated in the right pontine area.

Because of these discrepancies the SP elicited by supraorbital nerve stimulation was not studied systematically. The findings reported below refer to responses after stimulation of the second and third branches of the trigeminal nerve. The mean duration of the SP after infraorbital nerve stimulation was $51.4 \mathrm{~ms}$, 
ranging from 13 to $94 \mathrm{~ms}$, and after mental nerve stimulation $52.9 \mathrm{~ms}$, ranging from 15 to $98 \mathrm{~ms}$. The duration of the bilateral SPs may be equal or different (range: 0-6 ms; mean: $0.6 \mathrm{~ms}$ ), because of the difference in the end points (X). The mean latency time was $11.6 \mathrm{~ms}$ (range: $10-14 \mathrm{~ms}$ ). Of the 240 SPs studied, 96 showed an interruption caused by a recurrence of voluntary activity (V) (Fig. 1B and C).

The five normal subjects in whom only cutaneous afferent nerve fibres were stimulated by intracutaneous application of trains of electrical stimuli showed masseter SPs identical with the SP obtained by percutaneous single stimuli (Fig. 1C).

On the basis of clinical findings and observations made during surgery or necropsy combined with electrodiagnostic findings consisting of blink and jaw reflexes and masseter myograms, eight groups of patients were distinguished (Goor and Ongerboer de Visser, 1976; Ongerboer de Visser and Goor, 1976), as follows:

GROUP 1 Four patients had an isolated unilateral trigeminal motor root lesion, showing wasting of the masseter muscle, denervation potentials and no action potentials in the masseter EMG, no jaw reflex, normal sensation, and normal blink reflex. The patient in whom half of the mandible with the masseter muscle had been removed was assigned to this group on the basis of the results obtained after infraorbital nerve stimulation. The patients in this group had normal SPs on the normal sides after stimulation applied to both the normal and the affected sides (Fig. 4A).

GROUP 2 Three patients had a combined trigeminal motor and sensory root interruption. These patients showed the same motor root dysfunction as group 1 and also sensory root dysfunction: a hemifacial sensory loss and an afferent block in the blink reflex.

In this group no SPs were obtained on the contralateral side after stimulation applied to the affected sides. Stimulation on the normal side gave ipsilaterally normal SPs (Fig. 4B).

GROUP 3 Four patients had an isolated unilateral trigeminal sensory root lesion, and showed the same sensory root dysfunction as group 2 , no weakness of the masseter, and a normal jaw reflex and masseter EMG.

The patients in this group showed no SPs on either side after stimulation on the affected side, but
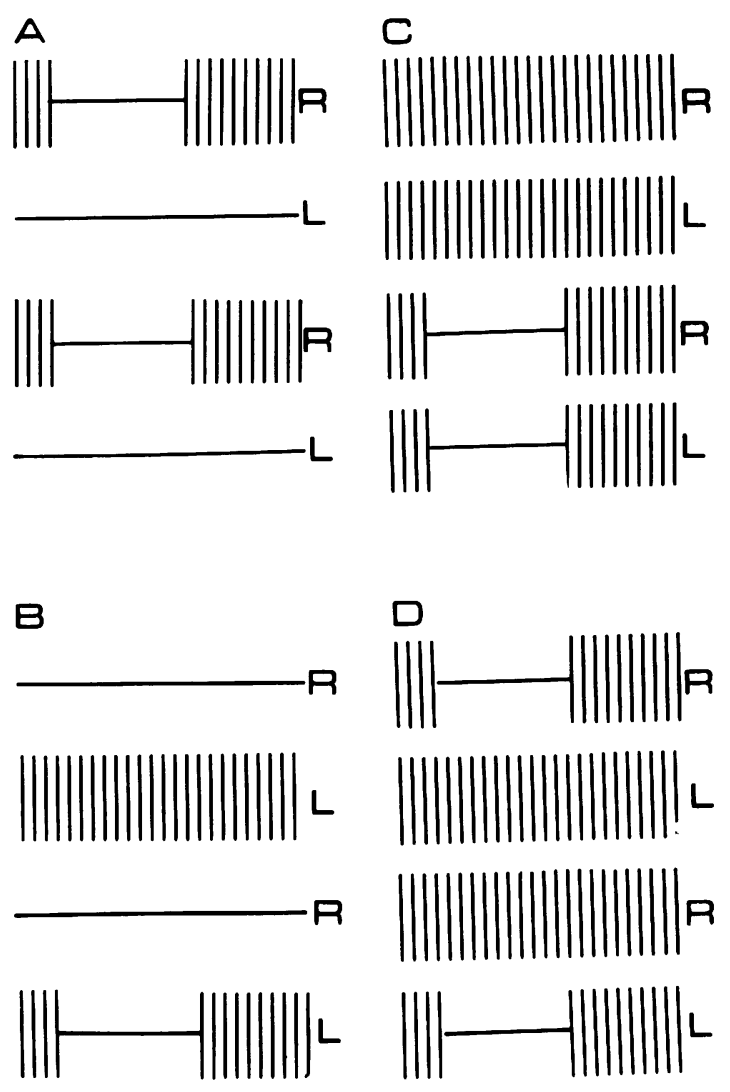

FIG. 4 Schematic representation of the findings concerning the masseter silent periods in the patient group. Upper two traces: stimulation on the right side. Lower two traces: stimulation on the left side. For discussion see text.

bilaterally normal SPs were obtained after stimulation of the normal side (Fig. 4C).

GROUP 4 Six patients had a lesion in afferent fibres of the trigeminal motor root outside the brain stem. Both voluntary masseter contraction and the masseter EMG were normal, but no jaw reflex could be evoked on the affected side. No abnormalities in the sensibility or the blink reflexes were found.

The patients of this group showed normal masseter SPs after stimulation applied ipsilaterally to the side lacking jaw reflexes.

GROUP 5 Three patients had unilateral midbrain lesions. The results in these patients were the same as those in group 4, including the normal masseter SP findings. 
GROUP 6 Two patients had pontine tumours. In the patient with the tumour located deep in the pons no abnormalities of the fifth cranial nerve function were detected; the jaw and blink reflexes were normal; a unilateral SP was recorded ipsilaterally on the stimulated side and no SP was seen on the contralateral side (Fig. 4D). The patient with a right pontine localization of the tumour showed the same fifth cranial nerve symptoms and electrodiagnostic results as indicated for group 3, including the masseter SP findings (Fig. 4C).

GROUP 7 Four patients had the Wallenberg syndrome. These patients showed a hemifacial sensory disturbance with an afferent delay in the blink reflex of the type reported by Kimura (1973), normal masticatory function, and a normal jaw reflex and masseter EMG.

This group had normal masseter SPs.

GROUP 8 Four patients had unilateral facial paralysis, an efferent block in the blink reflex, and normal jaw reflexes and masseter EMGs.

In this group the masseter SPs showed no abnormalities.

The mean SP duration in the 30 patients was $53.6 \mathrm{~ms}$ (range: 9-96 ms) and the mean latency $11.8 \mathrm{~ms}$ (range: $10-14 \mathrm{~ms}$ ).

\section{DISCUSSION}

The SPs recorded during maximal contraction of the masseter muscles showed identical characteristics in each individual. Interruptions caused by short periods of recurrence of EMG activity (Fig. 1B and C; V) did not always appear bilaterally and did not alter the end-point of the SP. This voluntary interference pattern is therefore regarded as break-through activity, as McLellan (1973) did for the same finding in the abductor pollicis brevis muscles after median nerve stimulation.

The results obtained after intracutaneous stimulation seem to support our hypothesis that cutaneous influences play a significant role in the method used in our study. With single percutaneous stimulation over the mental or infraorbital nerves stretched or distorted underlying facial muscles could also be involved in the SP response in the masseter musculature, but, as the results in the patients with facial paralysis (group 8) were similar to normal findings, this is very unlikely. Furthermore, even with the techniques we employed it remains possible that other than cutaneous inhibitory components are involved in the masseter silent period. Signals from masseter spindles were impeded in the patients with unilaterally absent jaw reflexes due to an afferent block (groups 4 and 5). Neither these signals nor antidromic motor impulses could exert an influence in the group of patients with a complete motor root interruption (group 1), all of whom showed contralaterally normal SPs. Impulses from tendon organs were certainly lacking in the patient in whom the masseter muscle had been excised and who had a contralaterally normal masseter SP after infraorbital nerve stimulation. The failure to evoke a silent period in the patients of group 3 with an interrupted trigeminal sensory root and an intact motor root demonstrates that the masseter SP is not influenced by the trigeminal motor root. On the basis of the present results it is therefore reasonable to suggest that the SP elicited in the masseter muscles by infraorbital or mental nerve stimulation is purely cutaneous in origin.

The bilaterally absent SP in the patients with a selective trigeminal sensory root interruption (group 3) (Fig. 4C), as opposed to the contralaterally normal SP findings in group 1 consisting of patients with a trigeminal motor root interruption (Fig. 4A) indicates that the SP reflex is transmitted through the trigeminal sensory root and crosses the midline. The SP reflex also travels uncrossed, as demonstrated by the patients of group 2 (one-sided complete interruption of the fifth nerve; Fig. 4B) and by the patient with the tumour in the mid-pontine region in group 6 (Fig. 4D). The normal SP findings in the cases with unilateral midbrain (group 5) or medullary lesions (group 7), both involving the trigeminal nerve centrally at these levels as opposed to the abnormal SP findings in the patients with pontine tumours (group 6), suggest that the masseter SP reflex is relayed through the pons and crosses the midline in this region. This suggestion is consistent with the findings in the cat made by Kidokoro et al. (1968a,b) after electrical stimulation of trigeminal exteroceptive fibres. They invariably found trigeminal motoneurone inhibition, making it probable that the SP reflex is transmitted in the region dorsomedial to the trigeminal motor nucleus in the pons. Axon collaterals of the 
inhibitory interneurones may cross the midline and impinge directly on the contralateral masseter motoneurones.

The results of the present study show that recording of the masseter SP reflex is a relatively simple electrodiagnostic method for the detection of trigeminal sensory root lesions. For a median pontine lesion the SP reflex (Fig. 4D) may be of special clinical interest, because this reflex seems to cross the midline in the pons, unlike such reflexes as the early blink, $\mathrm{H}$, and jaw reflexes passing through this region unilaterally (Kimura, 1973; Godaux and Desmedt, 1975; Goor and Ongerboer de Visser, 1976). In our patient with such a lesion the sensation and masticatory function as well as the jaw and blink reflexes showed no abnormalities. For such cases, and those with sensory root interruptions, the inhibitory phenomena evoked in the masseter muscles by the techniques we applied seem to offer a valuable supplement to the results of recorded brain stem reflexes travelling through the pontine level. The pontire lesions, however, require further study.

We are indebted to Dr L. J. Endtz and Dr H. A. C. Kamphuisen for their critical reading of the manuscript. We also wish to thank Miss J. E. M. Homan for assistance during the experiments and Miss E. A. S. C. van der Pool for secretarial assistance.

\section{REFERENCES}

Godaux, E., and Desmedt, J. E. (1975). Human masseter muscle: H- and tendon reflexes. Archives of Neurology (Chic.), 32, 229-234.

Goor, C., and Ongerboer de Visser, B. W. (1976). Jaw and blink reflexes in trigeminal nerve lesions: an electrodiagnostic study. Neurology (Minneap.), 26, 95-97.

Higgins, D. C., and Lieberman, J. S. (1968). The muscle silent period: variability in normal man. Electroencephalography and Clinical Neurophysiology, 24, 176-182.

Hoffman, P., and Tönnies, J. F. (1948). Nachweis des völlig konstanten Vorkommens des Zungen-Kieferreflexes beim Menschen. Pfügers Archiv, 250, 103-108.

Hufschmidt, H. J., and Spuler, H. (1962). Mono- and polysynaptic reflexes of the trigeminal muscles in human beings. Journal of Neurology, Neurosurgery, and Psychiatry, 25, 332-335.

Kidokoro, Y., Kubota, K., Shuto, S., and Sumino, R. (1968a). Reflex organization of cat masticatory muscles. Journal of Neurophysiology, 31, 695-708.

Kidokoro, Y., Kubota, K., Shuto, S., and Sumino, R. (1968b). Possible interneurons responsible for reflex inhibition of motoneurons of jaw-closing muscles from the inferior dental nerve. Journal of Neurophysiology, 31, 709-716.

Kimura, J. (1973). The blink reflex as a test for brainstem and higher central nervous function. In New Developments in Electromyography and Clinical Neurophysiology, vol. 3, pp. 682-691. Edited by J. E. Desmedt. Karger: Basel.

McIntyre, A. K. (1951). Afferent limb of the myotatic arc. Nature, 168, 168-169.

McIntyre, A. K., and Robinson, R. G. (1959). Pathway for the jaw-jerk in man. Brain, 82, 468-474.

McLellan, D. L. (1973). The electromyographic silent period produced by supramaximal electrical stimulation in normal man. Journal of Neurology, Neurosurgery, and Psychiatry, 36, 334-341.

Meier-Ewert, K., Gleitsman, K., and Reiter, F. (1974). Acoustic jaw reflex in man: its relationship to other brain-stem and microreflexes. Electroencephalography and Clinical Neurophysiology, 36, 629-637.

Ongerboer de Visser, B. W., and Goor, C. (1974). Electromyographic and reflex study in idiopathic and symptomatic trigeminal neuralgias: latency of the jaw and blink reflexes. Journal of Neurology, Neurosurgery, and Psychiatry, 11, 1225-1230.

Ongerboer de Visser, B. W., and Goor, C. (1976). Jaw reflexes and masseter myograms in mesencephalic and pontine lesions: an electrodiagnostic study. Journal of Neurology, Neurosurgery, and Psychiatry. 39, 90-92.

Shahani, B. T., and Young, R. R. (1973). Studies of the normal human silent period. In New Developments in Electromyography and Clinical Neurophysiology, vol. 3, pp. 589-602. Edited by J. E. Desmedt. Karger: Basel.

Struppler, A. (1975). Discussion of methodology and standardisation of silent period. Electromyography and Clinical Neurophysiology, 15, 169-173.

Struppler, A., Kessel, F. K., and Weidenbach, W. (1960). Elektrophysiologische Untersuchungen an de-afferentierten menschlichen Muskeln: Masseter-Studien. Medische Monatschrift, 14, 25-26.

Szentágothaï, J. (1948). Anatomical considerations of mono-synaptic reflex arcs. Journal of Neurophysiology, $11,445-454$.

Wilkins, R. H., and Brody, I. A. (1970). Wallenberg's syndrome. Archives of Neurology (Chic.), 22, 379-382. 